\title{
Caenorhabditis elegans Integrates the Signals of Butanone and Food to Enhance Chemotaxis to Butanone
}

\author{
Ichiro Torayama, Takeshi Ishihara, and Isao Katsura \\ Structural Biology Center, National Institute of Genetics, and Department of Genetics, The Graduate University for Advanced Studies, Mishima 411-8540, \\ Japan
}

\begin{abstract}
Behavioral plasticity induced by the integration of two sensory signals, such as associative learning, is an important issue in neuroscience, but its evolutionary origin and diversity have not been explored sufficiently. We report here a new type of such behavioral plasticity, which we call butanone enhancement, in Caenorhabditis elegans adult hermaphrodites: C. elegans specifically enhances chemotaxis to butanone by preexposure to butanone and food. Mutant analysis revealed that this plasticity requires the $\mathrm{AWC}^{\mathrm{ON}}$ olfactory neuron, whose fate is known to be determined by the NSY-1/ASK1 MAPKKK (mitogen-activated protein kinase kinase kinase) cascade as well as the DAF-11 and ODR-1 guanylyl cyclases. These proteins also control many aspects of olfactory sensation/plasticity in AWC neurons and seem to provide appropriate cellular conditions for butanone enhancement in the $\mathrm{AWC}^{\mathrm{ON}}$ neuron. Butanone enhancement also required the functions of Bardet-Biedl syndrome genes in the $\mathrm{AWC}^{\mathrm{ON}}$ neuron but not other genes that control ciliary transport. Furthermore, preexposure to butanone and the odor of food was enough for the enhancement of butanone chemotaxis. These results suggest that the AWC ${ }^{\mathrm{ON}}$ olfactory neuron may conduct a behavioral plasticity resembling associative learning and that the functions of Bardet-Biedl syndrome genes in sensory cilia may play an important role in this plasticity.
\end{abstract}

Key words: C. elegans; olfactory neuron; learning; Bardet-Biedl syndrome; chemotaxis; sensory cilia

\section{Introduction}

Animals sense a variety of environmental cues and change their behavior as a consequence of the experience. The mechanism of such behavioral plasticity is an important issue in neurobiology and investigated often by using model organisms with a simple nervous system such as the nematode Caenorhabditis elegans.

Despite its simple nervous system, C. elegans shows relatively complicated behavioral plasticity induced by simultaneous sensation of two different stimuli (Hedgecock and Russell, 1975; Colbert and Bargmann, 1997; Gomez et al., 2001; Saeki et al., 2001; Ishihara et al., 2002; Nuttley et al., 2002; Bettinger and McIntire, 2004; Chao et al., 2004; Mohri et al., 2005; Murakami et al., 2005; Remy and Hobert, 2005; Zhang et al., 2005; Kodama et al., 2006; Kuhara and Mori, 2006; Tomioka et al., 2006; Vellai et al., 2006). This type of plasticity must contain a process that integrates the two signals and therefore has been compared with associative learning. One of the signals, corre-

Received 0ct. 3, 2006; revised Dec. 4, 2006; accepted Dec. 5, 2006.

This work was supported by grants from the Ministry of Education, Culture, Sports, Science, and Technology of Japan. We are very grateful to Cori Bargmann, Yasushi Hiromi, and Koutarou Kimura for critically reading this manuscript and for giving many useful comments and to Sarah Bauer-Huang, Miri VanHoven, Cori Bargmann, Beth Sawin, and Bob Horvitz for sharing unpublished results. We thank Yuji Kohara for cDNA clones, Andy Fire for pPD vectors, Alan Coulson and A. Fraser for cosmid clones, Atsushi Miyawaki for venus CDNA, Hiroshi Kagoshima for odr-3 and str-1 promoters, Steven Wicks for single nucleotide polymorphism data, Shohei Mitani for tm 445 and tm501, Cori Bargmann for ky389gf, ky542, ky626, ky630, ky648, kyls140, and 0DR-1(0E), and the International C. elegans Gene Knockout Consortium for ok914. Some nematode strains were provided by the Caenorhabditis Genetics Center.

Correspondence should be addressed to Isao Katsura, Structural Biology Center, National Institute of Genetics, Mishima 411-8540, Japan. E-mail: ikatsura@lab.nig.ac.jp.

D01:10.1523/JNEUROSCI.4312-06.2007

Copyright $\odot 2007$ Society for Neuroscience $\quad$ 0270-6474/07/270741-10\$15.00/0 sponding to conditioned stimulus in associative learning, is a gustatory, olfactory, or temperature stimulus, whereas the other, corresponding to unconditioned stimulus, is usually starvation or food but sometimes ethanol or visceral malaise. In most cases, the signal of food seems to be mediated by serotonin. Exogenous serotonin has the same effect as food, and mutants in serotonin synthesis genes exhibit defects in the effect of food on many behaviors (Horvitz et al., 1982; Colbert and Bargmann, 1997; Sawin et al., 2000; Sze et al., 2000; Saeki et al., 2001; Nuttley et al., 2002; Remy and Hobert, 2005; Zhang et al., 2005).

We have been studying behavioral plasticity induced by AWC-sensed odorants and food. AWC neurons are bilateral ciliated olfactory neurons in the head that sense butanone, benzaldehyde, isoamyl alcohol, 2,3-pentanedione, etc. (Bargmann et al., 1993). The two AWC neurons look similar in structure but are different in the expression of the G-protein-coupled receptor STR-2, which is randomly expressed in either the left or the right AWC neuron but never in both (Troemel et al., 1999; Sagasti et al., 2001). The asymmetry is initiated by axon contact between the two AWC neurons, followed by the repression of calcium signaling and the NSY-1/ASK1 MAPKKK (mitogen-activated protein kinase kinase kinase) signaling in only one of them, in which STR-2 is expressed. The DAF-11 and ODR-1 guanylyl cyclases are required to maintain the STR-2 expression. There are also functional differences between the two AWC neurons: low concentrations of butanone can be detected only by the STR-2expressing $\left(\mathrm{AWC}^{\mathrm{ON}}\right)$ neuron, whereas low concentrations of 2,3-pentanedione only by the STR-2 nonexpressing (AWC ${ }^{\mathrm{OFF}}$ ) neuron (Wes and Bargmann, 2001).

In this study, we report a new type of behavioral plasticity, 
which we call "butanone enhancement." It is distinct from known behavioral plasticity induced by two sensory stimuli in either or both of the following two points: the unconditioned stimulus is food rather than starvation, and serotonin cannot substitute for food in this plasticity. Mutant analysis revealed that it is probably conducted in the AWC ${ }^{\mathrm{ON}}$ neuron and requires the functions of Bardet-Biedl syndrome genes, suggesting the importance of sensory cilia in this plasticity.

\section{Materials and Methods}

Worm culture and strains. Animals were cultivated on nematode growth medium (NGM) plates on the Escherichia coli strain OP50 by standard methods (Brenner, 1974). The wild-type strain of this study was C. elegans variation Bristol N2. Another wild-type strain CB4856 was used for single nucleotide polymorphism (SNP) mapping. The mutant strains used in this study are the following: olrn-1(ut305), nsy-6(ky626), olrn-2(ut306), nsy-1(ky542), daf-11(m84), nsy-7(ky630), nsy-8(ky648), slo-1(ky389gf), str-2(tm445), egl-4(n478), osm-9(ky10), sdf-13(ut180), tph-1(mg280), cat-1(e1111), cat-2(e1112), cat-4(e1141), tdc-1(ok914), ttx-3(mg158), hen-1(tm501), glr-1(ky176), eat-4(ky5), sra-13(zh13), egl3(n150), egl-21(n611), lim-4(ky403), che-1(p672), bbs-8(nx77), bbs1(ok1111), osm-12(n1606), osm-1(p808), osm-3(p802), dyf-1(mn335), daf-10(e1387), che-11(e1810), and che-2(e1033). nsy-6(ky626) was isolated by Miri VanHoven in the Bargmann laboratory (Rockefeller University, New York, NY) in the screening for mutants showing the AWCsymmetry phenotype and later found to be allelic to olrn-1(ut305) (S. Bauer-Huang and C. I. Bargmann, personal communication; our unpublished results). The two olrn-1/nsy- 6 mutants showed essentially the same phenotypes. olrn-2(ut306) was found to be allelic to $b b s-8(n x 77)$ in this study. ODR-1(OE) is an $o d r-1$ (n1936) mutant strain carrying highcopy transgenes of the wild-type odr-1 genomic clone, showing stronger expression of ODR-1 than N2 (L'Etoile and Bargmann, 2000). gpa-3(gf) is a strain with a chromosomal insertion (syIs $25 X)$ of the gain-offunction (Q205L) mutant gpa-3 transgenes, showing a cilium structure mutant phenotype as detected by the dye-filling test (Zwaal et al., 1997). The $n s y-7$ and $n s y-8$ mutants (M. VanHoven and C. I. Bargmann, personal communication), which show a 2 AWC ${ }^{\mathrm{OFF}}$ phenotype at the adult stage such as daf-11, exhibited weak defects in butanone enhancement and chemotaxis to 1:1000 butanone. The str-2(tm445) mutant showed normal butanone enhancement, indicating that the requirement of the str-2-expressing AWC neuron ( $\mathrm{AWC}^{\mathrm{ON}}$ ) is not attributable to the requirement of str-2 expression itself.

Behavioral assay. Chemotaxis assays were performed by standard methods (Bargmann and Horvitz, 1991; Bargmann et al., 1993). Approximately 100 animals were washed twice with S basal (Brenner, 1974) and once with distilled water. They were transferred to the center of a $9 \mathrm{~cm}$ chemotaxis assay plate containing $10 \mathrm{ml}$ of assay agar. Two microliters of the test odorant, diluted with ethanol, were placed at one end of the plate, and $2 \mu \mathrm{l}$ of the solvent (ethanol) at the other end. The dilutions (v/v) of the test odorants for chemotaxis assays were usually 1:10 for butanone and 1:200 for benzaldehyde. The dilution of butanone was exceptionally 1:1000 in the butanone adaptation experiments, and the dilution of benzaldehyde was exceptionally 1:35 in the experiments for testing the effect of preexposure to butanone and food. In selection assays, $2 \mu \mathrm{l}$ of the control odorant, also diluted with ethanol, was used instead of the solvent. The dilutions of the control odorants were 1:100 for isoamyl alcohol and 1:1000 for diacetyl, whereas the dilution of the test odorant, butanone, was 1:10. One microliter of $1 \mathrm{M} \mathrm{NaN}_{3}$ was placed at each end of the plate to paralyze the animals on arrival near each end. The chemotaxis index $(\mathrm{CI})$ was calculated as follows: $\mathrm{CI}=\{$ (number of animals at the test odorant) - (number of animals at the solvent or control odorant) $\} /$ (total number of animals tested). In the butanone enhancement experiment of slo-1(gf);olrn-1, which also carried a chromosomal insertion of str-2::green fluorescent protein (GFP) (kyIs140), all of the animals at the test odorant, the solvent, and the other place were picked separately after the chemotaxis assay and tested for their str-2 expression phenotype under a fluorescence microscope. The chemotaxis indexes for $2 \mathrm{AWC}{ }^{\mathrm{ON}}$, $1 \mathrm{AWC}^{\mathrm{ON}} / 1 \mathrm{AWC}^{\mathrm{OFF}}$, and $2 \mathrm{AWC}^{\mathrm{OFF}}$ animals, respectively, were cal- culated by using these data. Unless otherwise noted, chemotaxis and selection assays were conducted for $60 \mathrm{~min}$. The average and SEM of $4-15$ plates are presented in the figures, except for Figure $5 C$ (three plates for each data) and Figure $5 D$ (two to four plates). ${ }^{*} p<0.005$ and ${ }^{* *} p<$ 0.05 in the figures indicate statistically significant differences by the paired $t$ test.

The assay of butanone enhancement was based on the standard assay for adaptation (Colbert and Bargmann, 1995). Animals were washed twice with $S$ basal and once with distilled water and transferred to a $9 \mathrm{~cm}$ plate containing $10 \mathrm{ml}$ of NGM agar with or without E. coli OP50 (food) for preexposure. The agar contained $5 \mathrm{~mm}$ serotonin (Creatinine Sulfate Complex; Sigma, St. Louis, MO) when the effect of exogenous serotonin was tested. Odorant was distributed among six agar plugs on the lid of the plate, and the plate was sealed with Parafilm. After preexposure for 90 $\mathrm{min}$, the animals were washed twice with $\mathrm{S}$ basal and once with distilled water and tested for the chemotaxis assay or the selection assay as described above. The amounts of odorants used for the preexposure were $12 \mu \mathrm{l}$ in butanone enhancement, $30 \mu \mathrm{l}$ in the butanone adaptation, $1.8 \mu \mathrm{l}$ in benzaldehyde adaptation, and $12 \mu \mathrm{l}$ in isoamyl alcohol adaptation.

The experiments of butanone enhancement with butanone and the odor of food were conducted as follows. Thick lawn of the E. coli OP50 was grown on enriched peptone plates $[0.12 \% \mathrm{NaCl}, 2.5 \%$ agar, $2 \%$ BactoPeptone (Difco, Detroit, MI), $5 \mathrm{mg} / \mathrm{L}$ cholesterol, $1 \mathrm{~mm} \mathrm{MgSO}_{4}$, and $25 \mathrm{~mm}$ K-phosphate buffer, pH6.0]. The agar with the bacterial lawn ( $40 \mathrm{~cm}^{2}$ in total), together with the agar containing butanone, was placed on the lid of a $9 \mathrm{~cm}$ preexposure plate containing $10 \mathrm{ml}$ of NGM agar without food. There was a space of a few millimeters between the bacterial lawn and the worms on the NGM agar. The amount of butanone and the time length for preexposure were exceptionally $0.24 \mu \mathrm{l}$ and $60 \mathrm{~min}$ to reduce the effect of butanone adaptation and starvation. The number of worms on the preexposure plate was $<100$. Other experimental procedures were the same as those for butanone enhancement with butanone and food.

Mutant screening. Animals were mutagenized with ethyl methanesulfonate by the standard method (Brenner, 1974). Four to 10 mutagenized L4 animals ( $\mathrm{P} 0$ ) were placed on a $9 \mathrm{~cm}$ NGM plate and allowed to selffertilize for two generations. The F2 progeny were collected at the young adult stage, preexposed to $12 \mu \mathrm{l}$ of butanone in the presence of food, and tested for the selection assay. In the first selection assay, the test odorant was 1:10 butanone, and the control odorant was 1:10,000 isoamyl alcohol. The concentration of the control odorant was lower than the ordinary selection assay to ensure strict selection of mutants. Animals at isoamyl alcohol were collected, allowed to recover for $24 \mathrm{~h}$, and subjected to a second round of preexposure and the selection assay. In the second selection assay, the test odorant was 1:10 butanone, and the control odorant was 1:10,000 diacetyl. Animals at diacetyl were chosen as candidates of mutants defective in butanone enhancement. The progeny of 2500 mutagenized F1 animals (5000 genomes) were screened, and 10 mutants were isolated. Of these mutants, olrn-1(ut305) and olrn-2(ut306) were characterized in detail, because they showed the strongest defects but normal chemotaxis to 1:10 butanone. These mutants were outcrossed to wild-type animals eight times before detailed characterization.

Positional cloning of olrn-1 and olrn-2 genes. Mapping of olrn-1 (ut305) and olrn-2(ut306) was performed by using single nucleotide polymorphisms between the two wild-type strains, N2 and CB4856 (Wicks et al., 2001), in which CB4856 showed normal butanone enhancement like N2. The presence of these mutations was detected by the phenotype of butanone enhancement abnormality. olrn-1 mapped between R03A10.5 and C02C6.1 on the right of LGX. DNA fragments containing each predicted gene in this region were used for rescue experiments. olrn-2 mapped between K11G9 and T07H8 near the center of LGV. Cosmid clones in this region were tested for the rescue of the abnormality in butanone enhancement. The cosmid T25F10 as well as its PCR fragment containing only T25F10.2 was found to rescue the phenotype.

DNA constructs. For making the olrn-1::GFP construct, a DNA fragment containing a $5 \mathrm{~kb}$ upstream sequence and the olrn- 1 coding region was amplified by PCR by using the primers CGA CCC TGC CCA TTA GGC ATG CTT AAA CC and CGC CCG GTT CCT GAC CAC CGA CAC CTC GAA TCG CTC GACAAG and cloned into the pPD95.75 vector (A. 
Fire, Stanford University School of Medicine, Stanford, CA) in which the original GFP had been replaced by an improved version of yellow fluorescent protein (venus) (Nagai et al., 2002). For cell-specific expression of olrn-1 and olrn-2, we made constructs using the Fire vector pPD49.26, which was designed for ectopic expression. The olrn-1 cDNAs (yk662e1 and yk1471c01) and the olrn-2 cDNAs (yk1227h12, yk1343g05, and yk1227h12) were obtained from Yuji Kohara (National Institute of Genetics, Mishima, Japan).

Germ-line transformation. Germ-line transformation was performed by microinjection (Mello et al., 1991). The DNA concentrations were $10-20 \mathrm{ng} / \mu \mathrm{l}$ for the DNA to be tested, along with $5 \mathrm{ng} / \mu \mathrm{l}$ pmyo-3::GFP DNA and 50-100 ng/ $\mu \mathrm{l}$ carrier DNA for rescue experiments, and 100 $\mathrm{ng} / \mu \mathrm{l}$ for the olrn-1::GFP construct without marker or carrier DNA for expression studies.

Laser ablation. The AWC ${ }^{\mathrm{ON}}$ neuron of $\mathrm{N} 2$ animals was marked with str-2::GFP (kyIs140) and killed by laser microsurgery at the L1 or L2 larval stage (Bargmann and Avery, 1995). After the animals were grown to young adults, the absence of str-2::GFP fluorescence was confirmed. Mock-ablated animals were treated in the same way as $\mathrm{AWC}^{\mathrm{ON}}$-ablated animals except that the laser operation was not conducted. More than 65 $\mathrm{AWC}^{\mathrm{ON}}$-ablated and mock-ablated young adult animals were tested for the selection assay both after and without preexposure to butanone and food. Half of the animals were tested first for the selection assay without preexposure, allowed to recover on NGM plated with food, and then tested for the selection assay after preexposure. The other half of the animals were tested in the opposite order.

\section{Results}

Chemotaxis to butanone is enhanced by preexposure to butanone in the presence of food

To investigate how animals change their behavior by integrating two environmental signals, we developed a new assay method, using the nematode $C$. elegans. In this assay, C. elegans young adult hermaphrodites were exposed to the odorant butanone in the presence of the food E. coli, and the effect of this exposure was tested by chemotaxis to the same odorant (Fig. 1A). The dilution of butanone for chemotaxis was $1: 10 \times$, which was enough to be sensed by both $\mathrm{AWC}^{\mathrm{ON}}$ and $\mathrm{AWC}{ }^{\mathrm{OFF}}$ neurons. After exposure to butanone in the absence of food, animals adapted to the odorant and reduced the efficiency of chemotaxis, as reported previously (Colbert and Bargmann, 1995) (Fig. 1 B). In contrast, after exposure to the odorants in the presence food, animals exhibited a higher chemotaxis index to butanone than naive animals. This phenomenon cannot be explained by the inhibition of adaptation by food, which was reported by Nuttley et al. (2002) for benzaldehyde. Rather, animals seemed to integrate the signals of food and butanone to enhance chemotactic responses to butanone. We therefore named this behavioral plasticity butanone enhancement and investigated it in detail. Animals kept in the absence of butanone and food showed the same chemotaxis index as naive animals (data not shown).

We investigated various conditions for butanone enhancement. This plasticity was specific to the species of the odorant for chemotaxis, i.e., preexposure to butanone and food did not change the efficiency of chemotaxis to benzaldehyde, although benzaldehyde is sensed also by AWC neurons (Fig. $1 \mathrm{~B}$ ). Comparison of the dose-response curves of chemotaxis with and without the preexposure revealed that the preexposure increased the efficiency of chemotaxis in the range of dilution of $1 \times$ to $1: 1000 \times$ but not at very low concentrations (Fig. 1C). This suggests that the enhancement is not attributable to the increase in the affinity of the butanone receptor. The dose-response curve of naive animals showed that chemotaxis to $1: 10 \times$ or $1: 100 \times$ butanone was less efficient than chemotaxis to 1:1000 $\times$ butanone, which might suggest the presence of a mechanism for suppressing chemotaxis
A

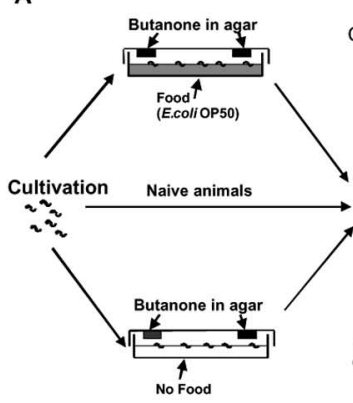

C

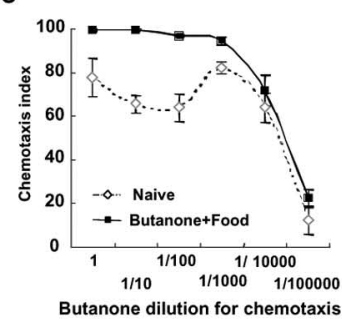

E

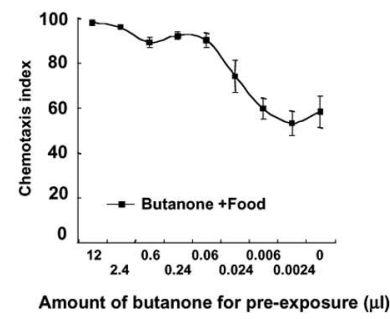

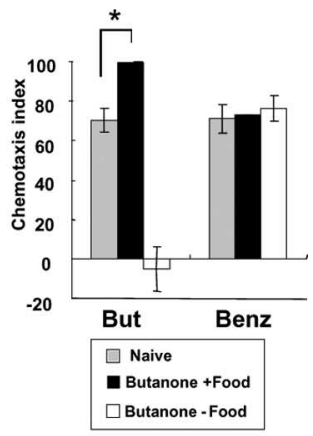

D

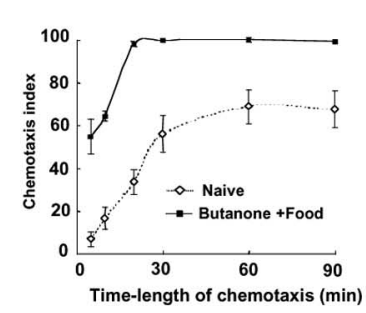

$\mathbf{F}$

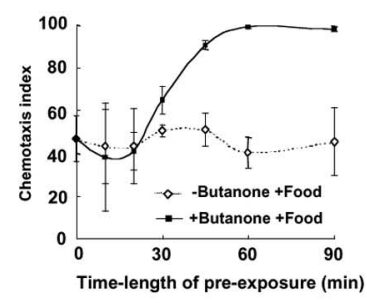

Figure 1. Characteristics of butanone enhancement. $\boldsymbol{A}$, The assay method of butanone enhancement. Animals preexposed to butanone in the presence (top) and absence (bottom) of food for $90 \mathrm{~min}$ and naive animals (middle) were tested for chemotaxis to the test odorant (top) or for selection between the test odorant and the control odorant (bottom) for $60 \mathrm{~min}$. $\boldsymbol{B}$, Preexposure to butanone and food enhanced chemotaxis of wild-type animals to butanone but not to benzaldehyde. Chemotaxis indexes to $2 \mu \mathrm{l}$ of 1:10 butanone (But) and $2 \mu \mathrm{l}$ of 1:35 benzaldehyde (Benz) without and after preexposure to $12 \mu$ l of butanone in the presence and absence of food. Animals kept in the absence of butanone and food showed the same chemotaxis indexes as naive animals, although the data are not shown. Fifteen plates were used for each data of butanone chemotaxis and eight plates for each data of benzaldehyde chemotaxis. ${ }^{*} p<0.005$, comparing naive animals and animals preexposed to butanone and food for butanone chemotaxis. Chemotaxis to benzaldehyde was conducted at various dilutions, but enhancement of chemotaxis by preexposure to butanone and food was not detected at all. $\boldsymbol{C}$ Dose-response curves of wild-type animals for chemotaxis to butanone after and without preexposure to butanone and food. The abscissa shows the dilution of butanone used for chemotaxis. At least six plates were used for all data. $D$, Dependence of chemotaxis indexes on the time length of chemotaxis to butanone after and without preexposure to butanone and food. Six plates were used for all data. $\boldsymbol{E}$, Dependence of chemotaxis indexes on the amount of butanone for preexposure in butanone enhancement. Butanone was diluted 2- to 10,000-fold with ethanol for preexposure. The abscissa shows the amount of butanone contained in the solution for preexposure. Four to six plates were used for all data. $\boldsymbol{F}$, Dependence of chemotaxis indexes on the time length of preexposure to butanone and food and to food without butanone (control). Six plates were used for all data. In all of these figures, the butanone dilution and the time length for chemotaxis were 1:10 $\times$ and $60 \mathrm{~min}$, whereas the amount of butanone and the time length for preexposure were $12 \mu \mathrm{l}$ and $90 \mathrm{~min}$, respectively, unless otherwise indicated. The error bars indicate SEM.

at high butanone concentrations. The dependence of chemotaxis indexes on the time length of chemotaxis revealed that both the initial speed of chemotaxis and the maximum chemotaxis index were increased by the preexposure (Fig. 1D). Only a small amount $(0.06 \mu \mathrm{l})$ of butanone was required for preexposure, whereas we used a much larger amount $(12 \mu \mathrm{l})$ in the standard 
Pre-exposure (90min) Interval (0-480min)

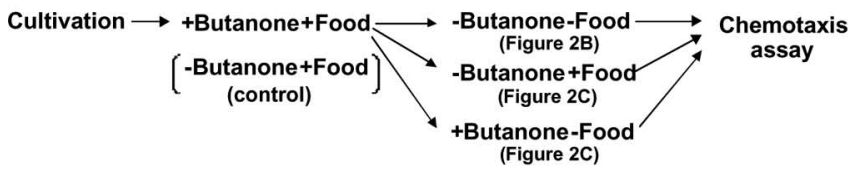

B
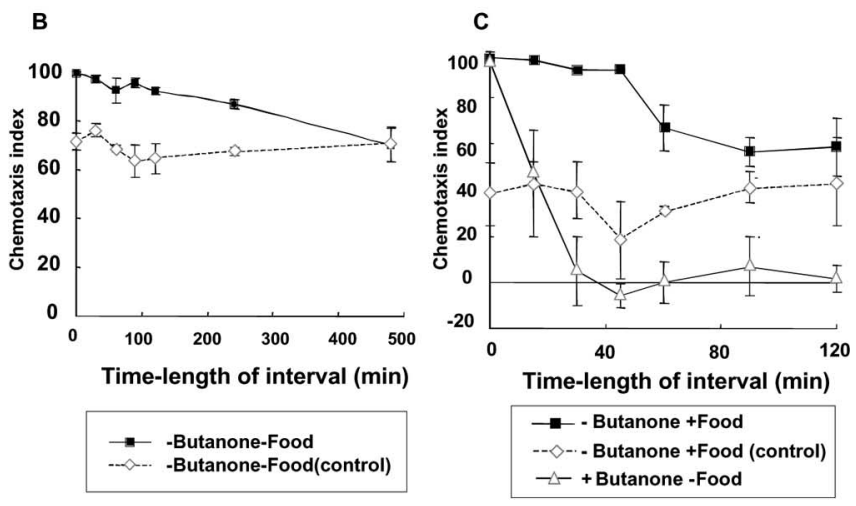

D

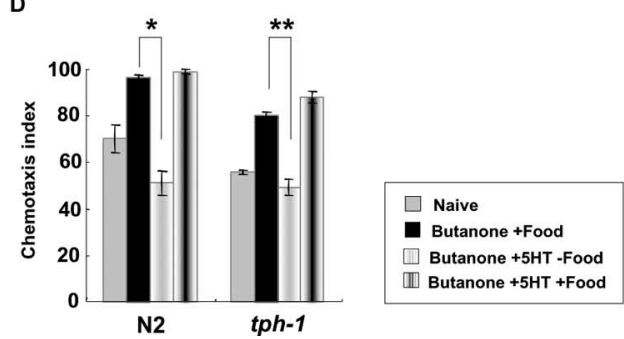

Figure 2. Memory duration and effect of serotonin on butanone enhancement. $\boldsymbol{A}$, Experimental scheme of memory duration experiments. Three conditions for the interval period were tested, while animals were normally preexposed to butanone and food but to food only in control experiments. $\boldsymbol{B}$, Memory duration of butanone enhancement. Wild-type animals were exposed to $12 \mu$ l of butanone with food (filled squares; butanone enhancement experiment) or food only (open rhombuses; control experiment), washed, kept on NGM plates without butanone and food for the time lengths indicated on the graph, and tested for chemotaxis to 1:10 butanone. The results showed that animals retained the memory for $4 \mathrm{~h}$ but not for $8 \mathrm{~h}$. Five to six plates were used for all data. C, "Unlearning" of butanone enhancement. Wild-type animals were exposed to $12 \mu$ l of butanone and food (filled squares; butanone enhancement) or food only (open rhombuses; control), washed, kept on NGM plates with food but without butanone for the time lengths indicated on the graph, washed, and tested for chemotaxis to 1:10 butanone. Triangles show the results of the experiment in which wild-type animals were exposed to $12 \mu$ l of butanone and food, washed, kept on NGM plates with $12 \mu \mathrm{l}$ of butanone without food, washed, and tested for chemotaxis to 1:10 butanone. The control experiment for the latter was not conducted. Animals lost the memory quicker in both cases than in experiments shown in $\boldsymbol{B}$. Six plates were used for all data. $\boldsymbol{D}$, The effects of the serotonin synthesis mutation $t p h-1$ and exogenous serotonin on butanone enhancement. "+ $5 \mathrm{HT}$ " means that exogenous seroto$\operatorname{nin}(5 \mathrm{~mm}$ ) was contained in the preexposure plates. Four to 15 plates were used for all data. ${ }^{*} p<0.005,{ }^{* *} p<0.05$, comparing "conditioning with butanone and food" with "conditioning with butanone and serotonin." The error bars indicate SEM.

assay (Fig. 1E). The dependence on the time of preexposure showed that the effect was detected at $30 \mathrm{~min}$ and saturated at 60 min, whereas we used $90 \mathrm{~min}$ in the standard assay (Fig. $1 F$ ).

The duration of the memory of preexposure was investigated by changing the length of the interval between the end of preexposure and the start of chemotaxis (Fig. $2 \mathrm{~A}$ ). When the animals were kept in the absence of butanone and food during the interval, the memory lasted for $4 \mathrm{~h}$ but not $8 \mathrm{~h}$ (Fig. $2 \mathrm{~B}$ ). In contrast, when animals were kept in the absence of butanone but presence of food, the chemotaxis index decreased more quickly (in $1 \mathrm{~h}$ ) to the level of naive animals (Fig. 2C). This may be interpreted as a kind of unlearning or dissociation of butanone and food signals. In the presence of butanone but absence of food, the chemotaxis index fell off in $30 \mathrm{~min}$ to a very low level as a result of adaptation to butanone (Fig. $2 C$ ). The memory ( $>4 \mathrm{~h}$ ) seems to be kept longer than other memories of smell, taste, or temperature (Colbert and Bargmann, 1995, 1997; Gomez et al., 2001; Saeki et al., 2001; Mohri et al., 2005), except the memory of olfactory imprinting (Remy and Hobert, 2005), which lasts for a lifetime but can be gained only at the L1 larval stage.

Although the presence of food during preexposure was essential, butanone enhancement did not seem to require serotonin, unlike other food-modulated behaviors in C. elegans. Mutants in serotonin synthesis genes ( $t p h-1$, cat-4) (Sulston et al., 1975; Sze et al., 2000) and a gene required for the vesicular transport of monoamines (cat-1) (Duerr et al., 1999) showed normal butanone enhancement (Fig. $2 D$ and data not shown). Preexposure to butanone in the presence of $5 \mathrm{~mm}$ serotonin did not enhance chemotaxis to butanone, although adaptation to butanone was partially inhibited. Besides mutants in serotonin synthesis and secretion, the following mutants showed normal butanone enhancement (data not shown): (1) mutants in olfactory adaptation, osm-9, egl-4, and sdf-13/Ce-tbx-2 (Colbert and Bargmann, 1995; L'Etoile et al., 2002; Miyahara et al., 2004), (2) mutants in dopamine synthesis (cat-2) (Sulston et al., 1975) and synthesis of tyramine and octopamine (tdc-1) (Alkema et al., 2005), (3) mutants in the differentiation $(t t x-3)$ and a function (hen-1) of AIY interneurons, which often play essential roles in sensory integration and behavioral plasticity (Gomez et al., 2001; Ishihara et al., 2002; Remy and Hobert, 2005), (4) mutants in glutamatergic synaptic transmission ( $g l r-1$, eat-4), which show abnormality in mechanosensory habituation (Rankin and Wicks, 2000; Rose et al., 2003), (5) a mutant in a G-protein-coupled receptor that downregulates the activity of AWC neurons ( $r r a-13)$ (Battu et al., 2003), (6) mutants in the processing of neuropeptides (egl-3, egl-21) (Kass et al., 2001; Jacob and Kaplan, 2003), and (7) mutants in the specific fate and functions of AWB neurons (lim-4) and ASE neurons (che-1) (Sagasti et al., 1999; Uchida et al., 2003).

\section{Isolation and characterization of mutants that show abnormality in butanone enhancement}

Because butanone enhancement did not require known plasticity genes, we decided to newly isolate mutants that show abnormality in this function. For this purpose, we modified the assay by using a control odorant (Fig. $1 \mathrm{~A}$, bottom right). In the chemotaxis assay, we put the solvent on the other side of the test odorant, as a control. In contrast, in the modified assay, which we call selection assay, we put a control odorant (isoamyl alcohol or diacetyl) instead of the solvent and let the animals select between the control odorant and the test odorant (butanone). The concentrations of the odorants were determined so that a majority of naive animals migrated to the former, whereas a majority of preexposed animals migrated to the latter (Fig. 3A, right, N2).

Using the selection assay after preexposure to butanone and food (see Materials and Methods), we isolated 10 mutants that showed abnormality in butanone enhancement and named them olrn (olfactory learning) mutants. Two of them, olrn-1(ut305) and olrn-2(ut306), which showed the strongest abnormality among these mutants, were characterized further. Without preexposure, both olrn-1 and olrn-2 animals exhibited normal chemotaxis to $1: 10$ butanone (Fig. $3 A$ ). After exposure to butanone in the absence of food, they showed normal adaptation to butanone. However, after exposure to butanone in the presence of food, the mutants did not increase but decreased their response 
A

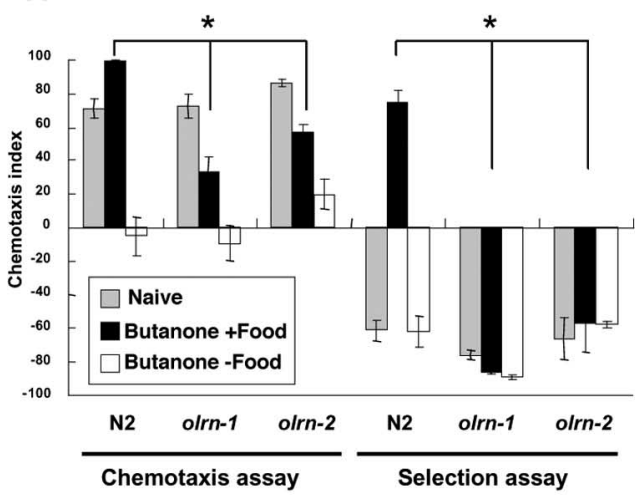

B

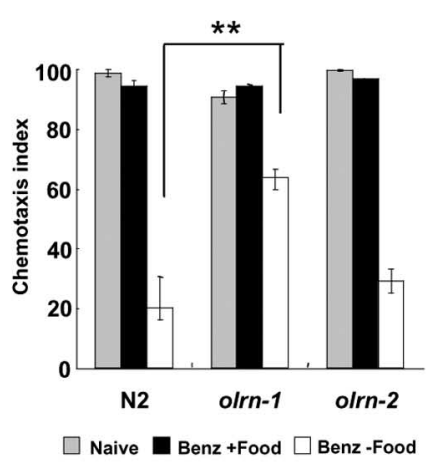

C
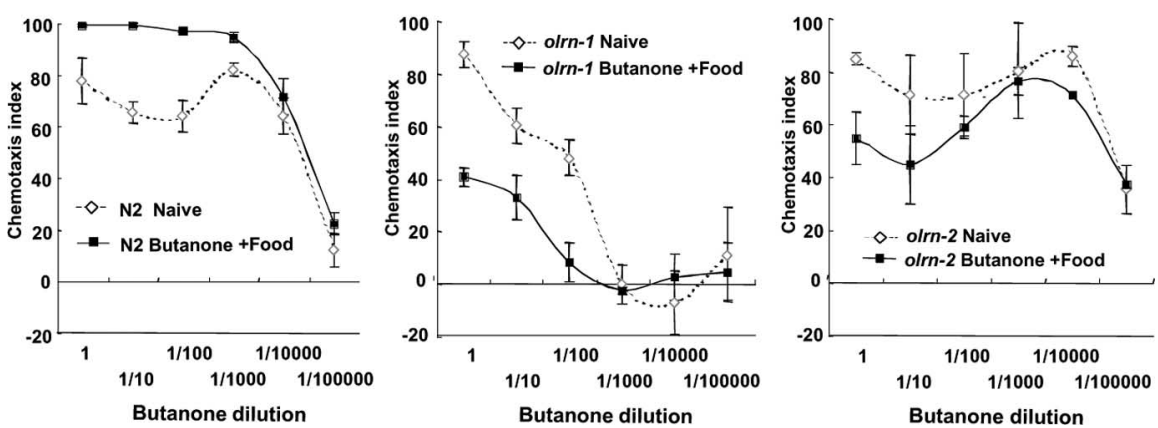

Figure 3. Effect of olrn-1(ut305) and olrn-2(ut306) mutations on butanone enhancement and benzaldehyde adaptation. $\boldsymbol{A}$, The olrn- 1 and olrn-2 mutants showed defects in butanone enhancement. The results of both the chemotaxis and selection assay are presented. The experimental conditions were the same as Figure $1 B$, and the control odorant in the selection assay was 1:1000 isoamyl alcohol. ${ }^{*} p<0.005$, comparing the wild-type (N2) animal with the olrn-1 and olrn-2 mutants, respectively, for butanone enhancement. Four to 15 plates were used for all data. $\boldsymbol{B}$, The olrn- 1 mutant but not the olrn-2 mutant showed abnormality in adaptation to benzaldehyde. Chemotaxis to 1:200 benzaldehyde was conducted after and without exposure to $1.8 \mu \mathrm{l}$ of benzaldehyde. Eight plates were used for "N2, Benz + Food" and 10 plates for "olrn-1, Benz + Food", whereas five to eight plates were used for other data. ${ }^{* *} p<0.05$, comparing the wild-type (N2) animal with the olrn-1 mutant for adaptation. C, The doseresponse curves of wild-type (N2), olrn-1, and olrn-2 animals for chemotaxis to butanone after and without exposure to $12 \mu \mathrm{l}$ of butanone and food. The abscissas show the dilution of butanone used for chemotaxis. The figure for $\mathrm{N} 2$ is the same as Figure $1 \mathrm{C}$. Four to 10 plates were used for all data. The error bars indicate SEM.

to butanone, as if they had defects in the sensation of food, integration of the signals of butanone and food, or formation of the memory. In the selection assay, they migrated to the control odorant even after exposure to butanone and food, as expected.

Figure $3 C$ shows the dose-response curves of butanone chemotaxis with and without preexposure to butanone and food for N2, olrn-1, and olrn-2 animals. olrn-1 animals exhibited defects in chemotaxis to 1:1000 and lower concentrations of butanone. At higher concentrations of butanone, olrn-1 animals did not increase but decreased the chemotaxis index by preexposure. Besides these abnormalities, olrn-1 animals showed abnormality in adaptation to benzaldehyde and isoamyl alcohol (Fig. $3 B$ and data not shown). In contrast, olrn-2 animals showed normal chemotaxis to butanone at all concentrations and decreased the chemotaxis index by preexposure especially at the butanone dilutions of $1 \times$ to $1: 100 \times$.

\section{olrn-1 encodes a novel protein required for producing the} $\mathrm{AWC}^{\mathrm{ON}}$ neuron

We cloned the olrn-1 gene by positional cloning. Genomic DNA fragments containing C02C6.2 gene could rescue all of the olrn-1 phenotypes, namely, butanone enhancement, chemotaxis to 1:1000 butanone, and adaptation to benzaldehyde (Fig. 4A). The WormBase (http://www.wormbase.org/; release WS160) showed

that C02C6.2 gene produces two types of transcripts (a- and b-types), which differ in short $5^{\prime}$ sequences (Fig. $4 B$ ). They encoded proteins of 561 and 554 amino acids, respectively, both containing three predicted transmembrane domains. The amino acid sequences showed partial homology to the fruit fly Raw protein, which is required for the restriction of JNK (cJun N-terminal protein kinase) signaling in embryogenesis (Byars et al., 1999). The ut305 mutation was located at the spliceacceptor site of the fourth intron (AG to $\mathrm{AA}$ ), between the second and the third predicted transmembrane domain in the corresponding amino acid sequence. Another allele of olrn-1, ky626, which was isolated in the Bargmann laboratory, showed essentially the same phenotypes as ut305. Detailed molecular characterization of the C02C6.2 gene is going on in the Bargmann laboratory (Bauer-Huang and Bargmann, personal communication).

A functional olrn-1::GFP fusion gene was expressed in many pharyngeal neurons and some head neurons (data not shown). To examine in which cell the olrn-1 gene acts for butanone enhancement, a full-length C02C6.2b cDNA was fused to a variety of cell-specific promoters and introduced into olrn-1 mutant animals. The phenotypes of the transformants revealed that expression of the wildtype olrn-1 gene in AWC neuron is required for butanone enhancement, chemotaxis to 1:1000 butanone, and adaptation to benzaldehyde (Fig. $4 C$ and data not shown).

The same experiments showed that a DNA construct with the str-2 promoter, which drives expression in the $\mathrm{AWC}^{\mathrm{ON}}$ neuron in wild-type animals, could not rescue the mutant phenotypes. We therefore examined the expression of str-2::GFP in olrn-1 mutants and found that it was expressed in neither of the AWC neurons ( $2 \mathrm{AWC}^{\mathrm{OFF}}$ phenotype). The result also explained why olrn-1 mutants showed defects in chemotaxis to 1:1000 butanone (Wes and Bargmann, 2001). The $2 \mathrm{AWC}^{\mathrm{OFF}}$ phenotype was rescued also by the expression of the wild-type olrn-1 in AWC neurons.

The $\mathrm{AWC}^{\mathrm{ON}}$ neuron is required for butanone enhancement The $2 \mathrm{AWC}^{\mathrm{OFF}}$ phenotype of olrn-1 animals suggested that the $\mathrm{AWC}^{\mathrm{ON}}$ neuron might be required for butanone enhancement. The following experimental results indicated that this was actually the case. (1) The $2 \mathrm{AWC}^{\mathrm{ON}}$ mutation $n s y$-1(ky542) was epistatic to olrn-1(ut305) in the str-2::GFP expression and suppressed all of the olrn-1 mutant phenotypes (Fig. $5 A, B$ and data not shown). (2) Another 2 AWC $^{\text {OFF }}$ mutant, daf-11(m84), also showed abnormality in butanone enhancement and chemotaxis to $1: 1000$ butanone, although the mutant showed normal adaptation to benzaldehyde (Fig. $5 A, B, E$ ). (3) slo-1 gene encodes a BK $\mathrm{K}^{+}$channel, and its gain-of-function mutation slo-1( $\left.k y 389 \mathrm{gf}\right)$ shows a 2 AWC $^{\text {ON }}$ phenotype (Sagasti et al., 2001; Davies et al., 2003). The slo-1(ky389gf);olrn-1(ut305) double-mutant animals 
consisted of those expressing str-2::GFP in two, one, and neither of the AWC neurons, respectively, and showed a butanone enhancement phenotype intermediate between slo-1 (gf) and olrn-1 (Fig. 5A). These animals were tested for a more detailed butanone enhancement assay in which the chemotaxis indexes for $2 \mathrm{AWC}^{\mathrm{ON}}, 1$ $\mathrm{AWC}^{\mathrm{ON}} / 1 \mathrm{AWC}^{\mathrm{OFF}}$, and $2 \mathrm{AWC}^{\mathrm{OFF}}$ animals, respectively, were calculated separately (Materials and Methods). The results clearly indicated that $2 \mathrm{AWC}^{\mathrm{ON}}$ and 1 $\mathrm{AWC}^{\mathrm{ON}} / 1 \mathrm{AWC}^{\mathrm{OFF}}$ animals were normal, but $2 \mathrm{AWC}^{\mathrm{OFF}}$ animals were defective in butanone enhancement, despite the fact that all of these animals had the same genotype (Fig. 5C). (4) Finally, the AWC ${ }^{\mathrm{ON}}$ neuron in wild-type animals was killed by laser microsurgery at the L1 larval stage, and the animals were tested for butanone enhancement after they grew to adults. The results revealed that $\mathrm{AWC}^{\mathrm{ON}}$-ablated wild-type animals were abnormal in butanone enhancement (Fig. 5D). Thus, olrn-1 gene regulates the cell-fate determination of $\mathrm{AWC}^{\mathrm{ON}} / \mathrm{AWC}^{\mathrm{OFF}}$ upstream of the NSY-1/ASK1 MAPKKK cascade, and olrn-1 mutants show defects in butanone enhancement because they do not have the $\mathrm{AWC}^{\mathrm{ON}}$ neuron.

\section{$2 \mathrm{AWC}^{\mathrm{ON}}$ mutants show defects in butanone adaptation}

Because 2 AWC $^{\text {OFF }}$ mutants showed defects in butanone enhancement, we suspected that $2 \mathrm{AWC}^{\mathrm{ON}}$ mutants might show defects in a different type of behavioral plasticity. It is known that animals overexpressing the guanylyl cyclase ODR-1 [abbreviated as ODR-1(OE) below] show an incompletely penetrant $2 \mathrm{AWC}^{\mathrm{ON}}$ phenotype (Wes and Bargmann, 2001) and a defect in adaptation to butanone (L'Etoile and Bargmann, 2000). We therefore hypothesized that other $2 \mathrm{AWC}^{\mathrm{ON}}$ mutants may also show defects in adaptation to butanone. This was verified by experiments in which $n s y$ - 1 and slo- $1(g f)$ mutants were tested for butanone adaptation (Fig. 5E). Because the AWC ${ }^{\mathrm{OFF}}$ neuron cannot sense 1:1000 butanone, which was used for chemotaxis in these experiments, the results suggest that the $\mathrm{AWC}^{\mathrm{ON}}$ neuron in $2 \mathrm{AWC}^{\mathrm{ON}}$ animals and that in wild-type animals have different properties concerning butanone adaptation.

\footnotetext{
The functions of Bardet-Biedl syndrome genes in the $\mathrm{AWC}^{\mathrm{ON}}$ neuron are required for butanone enhancement

We also cloned the olrn-2 gene, whose mutant exhibited defects in butanone enhancement without showing defects in chemotaxis to 1:1000 butanone, adaptation to benzaldehyde, or expression of str-2 gene (Fig. 3 B, C and data not shown). olrn-2(ut306) mapped near the center of LGV, and genomic DNA fragments containing only T25F10.5 gene rescued the butanone enhancement abnormality of olrn-2(ut306). The ut306 mutation was located at the splice donor site of the first intron (GT to AT). Expression of the wild-type olrn-2 cDNA by various extrinsic promoters revealed that olrn-2 gene acts in the $\mathrm{AWC}^{\mathrm{ON}}$ neuron for butanone enhancement (Fig. 6A).
}

\section{B}

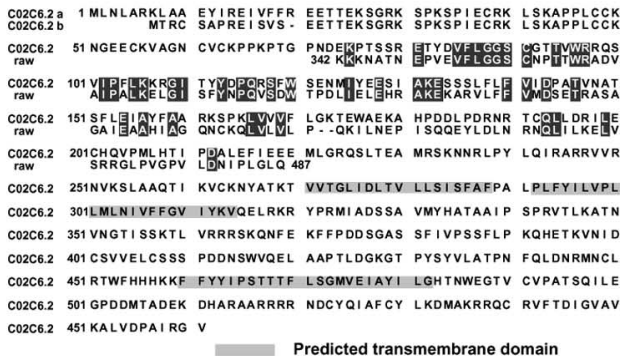

Predicted transmembrane domain

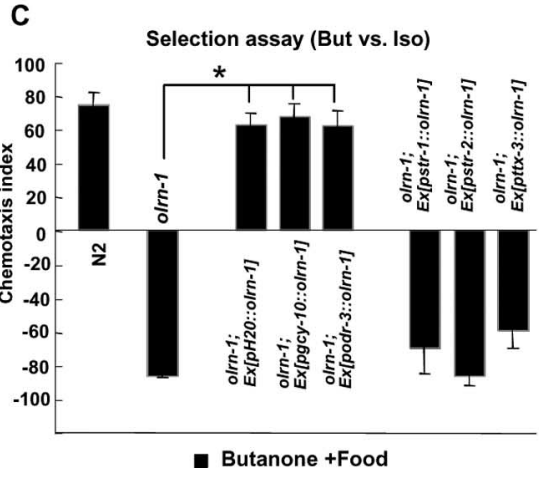

Figure 4. Cloning and expression of olrn-1 gene and cell-specific rescue of the olrn-1(ut305) butanone enhancement phenotype. $\boldsymbol{A}$, Genetic map, physical map, and genomic rescue experiments. The bottom indicates the regions of the genome used for

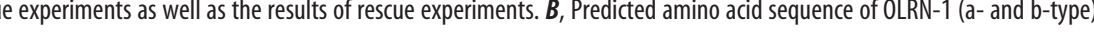
rescued all of the olrn-1 mutant phenotypes. Four to six plates were used for all data. ${ }^{*} p<0.005$, comparing the olrn- 1 mutant with the olrn-1 mutant carrying transgenes. The error bars indicate SEM. Iso, Isoamyl alcohol.

olrn-2 gene was allelic to $b b s-8$, one of the Bardet-Biedl syndrome genes, in which Bardet-Biedl syndrome is a genetically heterogeneous human developmental disorder characterized by a pleiotropic phenotype that includes obesity, rod-cone dystrophy, renal malformations, polydactyly, cognitive impairment, and several other aliments such as congenital heart defects and diabetes (Blacque et al., 2004). It is known that $b b s-8$ gene is expressed in ciliated sensory neurons (Ansley et al., 2003) and that mutations in $b b s-8$ gene cause structural defects in cilia (Blacque et al., 2004), which was also true for the olrn-2(ut306) mutation as detected by the dye-filling test (Starich et al., 1995). Furthermore, the $b b s-8(n \times 77)$ mutant as well as mutants in other bbs genes, bbs-1(ok1111) and osm-12(=bbs-7)(n1606) also showed defects in butanone enhancement (Fig. $6 B$ ).

Because $b b s$ mutations lead to partial loss of distal ciliary segments (Blacque et al., 2004), we examined butanone enhancement of other mutants that were known to show abnormality in cilium structure (Perkins et al., 1986; Zwaal et al., 1997; Ou et al., 2005). Mutants exhibiting various cilium defects, such as osm3(p802), dyf-1(mn335), daf-10(e1387), che-11(e1810), and gpa$3(g f)$, showed normal butanone enhancement (Fig. 6C). Even osm-1(p808) and che-2(e1033) mutants, which have very short cilia, increased their chemotaxis index by preexposure to butanone and food, although their chemotaxis index after the preexposure was still lower that that of wild-type animals. These results indicate that the abnormality in butanone enhancement is specifically related to defects in $b b s$ mutants but not in other cilium structure mutants. 
A

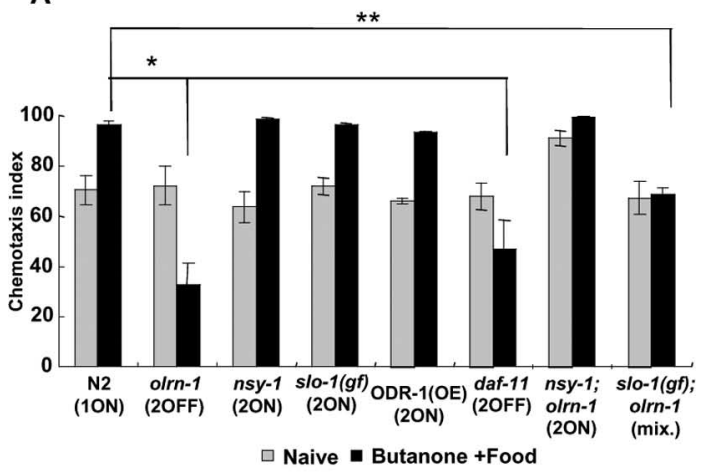

B

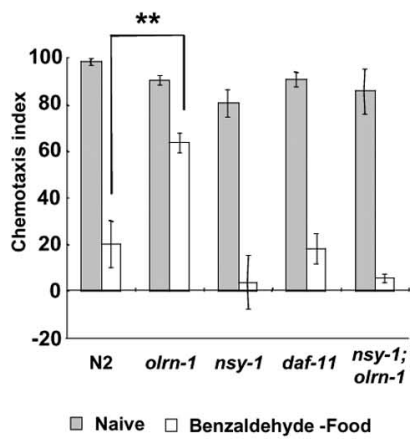

C

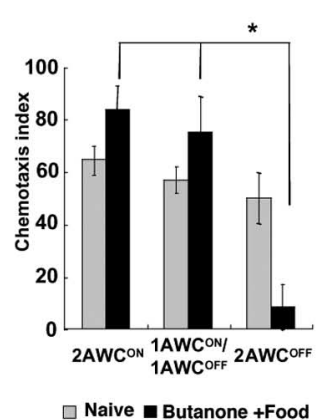

D

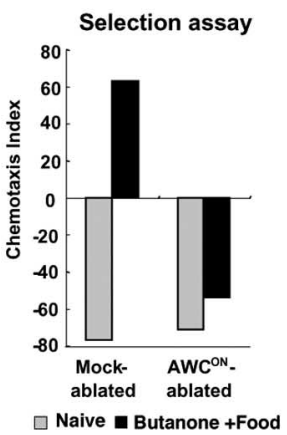

E

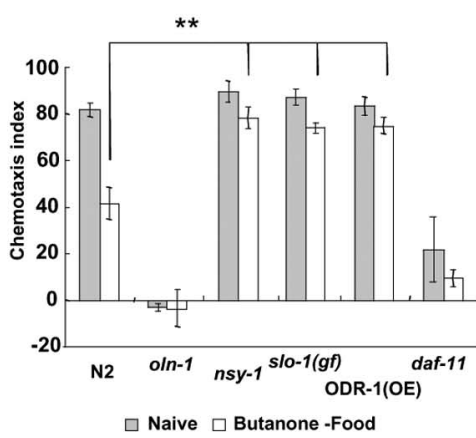

Figure 5. Effect of AWC symmetry mutations on butanone enhancement, adaptation to benzaldehyde, and adaptation to butanone. $\boldsymbol{A}$, Effect of AWC symmetry mutations on butanone enhancement. The AWC symmetry phenotypes are shown below the genotype: "10N," "20FF," and "20N" indicate 1 AWC ${ }^{\mathrm{ON}} / 1$ AWC ${ }^{\mathrm{OFF}}$ (the wild-type phenotype), 2 AWC ${ }^{\text {OFF }}$, and 2 AWC ${ }^{\text {ON }}$ phenotypes, respectively, whereas the double-mutant $10-1(\mathrm{gf})$; olrn-1 produces animals of all the three phenotypes. 0DR- $1(0 \mathrm{E})$ is an odr-1(n1936) mutant strain carrying high-copy transgenes of the wild-type odr-1 genomic clone. Four to 15 plates were used for all data. ${ }^{*} p<0.005,{ }^{* *} p<0.05$, comparing the wild-type (N2) animal with the olrn-1, daf-11, and s/o-1 (gf);olrn-1 mutants, respectively, for butanone enhancement. The dilution of butanone for chemotaxis was 1:10 (standard assay). $\boldsymbol{B}$, Adaptation to benzaldehyde of olrn-1,nsy-1, daf-11, and nsy-1;0/rn-1 mutants. Chemotaxis to 1:200 benzaldehyde was conducted without and after exposure to $1.8 \mu$ l of benzaldehyde in the absence of food. Five to 15 plates were used for all data. ${ }^{* *} p<0.05$, comparing the wild-type (N2) animal with the olrn-1 mutant for adaptation. $C$, The results of butanone enhancement assay (chemotaxis assay) for 2 AWC $^{\mathrm{ON}}, 1 \mathrm{AWC}^{\mathrm{ON}} / 1 \mathrm{AWC}{ }^{\mathrm{OFF}}$, and 2 AWC ${ }^{\mathrm{OFF}}$ animals, respectively, all having the genotype of slo-1 (gf); $0 / \mathrm{lrn}-1 .{ }^{*} p<$ 0.005 , comparing $2 \mathrm{AWC}^{\mathrm{OFF}}$ animals with $2 \mathrm{AWC}^{\mathrm{ON}}$ and $1 \mathrm{AWC}^{\mathrm{ON}} / 1 \mathrm{AWC}{ }^{\mathrm{OFF}}$ animals, respectively, for butanone enhancement. Three plates were used for all data. $\boldsymbol{D}$, The results of butanone enhancement assay (selection assay between 1:10 butanone and 1:100 isoamyl alcohol) for mock-ablated and AWC ${ }^{\mathrm{ON}}$-ablated wild-type animals. The selection assay was used to detect the butanone enhancement phenotype with a small number of animals (65-149 animals for each experiment). Each datum represents the result of selection assay using two to four plates. $\boldsymbol{E}$, Adaptation to butanone of olrn-1, nsy-1, slo-1(gf), 0DR-1(OE), and daf-11 mutants. Chemotaxis to 1:1000 butanone for 60 min was conducted without and after exposure to $30 \mu l$ of butanone in the absence of food for $90 \mathrm{~min}$. Four to six plates were used for all data. ${ }^{* *} p<0.05$, comparing the wild-type (N2) animal with the nsy-1 mutant, slo-1 (gf) mutant, and ODR-1(0E), respectively, for adaptation. This figure also shows defective chemotaxis of olrn-1 and daf-11 mutants to 1:1000 butanone. The error bars indicate SEM.

\section{Mechanism of food sensation in butanone enhancement}

The best known food signaling pathways in C. elegans are those for the modulation of locomotion rates of well fed and starved animals by food (Sawin et al., 2000). We tested the olrn-1(ut305) and olrn-2(ut306) mutants for these behaviors and found that both of them were normal (data not shown). This is consistent with the results that butanone enhancement is independent of serotonin and dopamine. It also shows that, if olrn-1 or olrn-2 is involved in food sensation, the mechanism for food sensation in butanone enhancement must be different from that in the modulation of locomotion rates.

To learn about the mechanism of food sensation in butanone enhancement, we conducted experiments in which animals were preexposed to butanone and the odor of food and then tested for chemotaxis to butanone. Wild-type animals preexposed in this way showed a higher chemotaxis index than those preexposed to butanone alone but a lower chemotaxis index than naive wild-type animals (Fig. 7). The reason, we thought, may be that the odor of food, unlike food itself, cannot inhibit butanone adaptation efficiently. We therefore used the osm-9(ky10) mutant, which shows poor butanone adaptation (Colbert and Bargmann, 1995) but normal butanone enhancement. As expected, osm-9 animals preexposed to butanone and the odor of food showed a higher chemotaxis index than naive osm-9 animals, although they still showed a lower chemotaxis index than osm-9 animals preexposed to butanone and food. The osm-9(ky10);olrn-2(ut306) double mutant, a negative control, did not increase its chemotaxis index by preexposure to butanone and the odor of food. These results indicate that the odor of food accounts for a considerable part, if not all, of the food signal in butanone enhancement. They also give information on the neurons that sense food for butanone enhancement. Of the neurons that were reported to sense odors (AWA, AWB, AWC, $\mathrm{ASH}$, and ADL), AWA, ASH, and ADL can be excluded from the candidates, because they require $o s m-9$ gene for odor sensation (Colbert et al., 1997; Tobin et al., 2002). AWB may also be excluded, because the lim-4(ky403) mutant, which has defects in the differentiation of AWB neurons (Sagasti et al., 1999), showed normal butanone enhancement (data not shown). Therefore, it is likely that AWC neurons sense a major part of the food odor for butanone enhancement, although other possibilities are not completely rejected.

\section{Discussion}

Butanone enhancement: a newly characterized behavioral plasticity in C. elegans

We characterized butanone enhancement, i.e., specific enhancement of butanone chemotaxis by preexposure to butanone and food. It is distinct from other foodrelated behavioral plasticities in C. elegans, because it does not require serotonin, which is required for the modulation of many behaviors by food. Furthermore, it does not depend on genes that act in known behavioral plasticities, as far as we checked. Butanone enhancement resembles olfactory imprinting in that preexposure to an odorant in the presence of food enhances chemotaxis to the same odorant but not to other odorants (Remy and Hobert, 2005). However, in the latter plasticity, preexposure must be conducted at the $\mathrm{L} 1$ stage, serotonin can replace for food, and $t t x-3$ mutations block the plasticity, unlike butanone enhancement.

This type of plasticity is not limited to butanone. Our laboratory found similar chemotaxis enhancement with 2,3pentanedione and isoamyl alcohol (H. Ichijo, I. Torayama, K. D. 

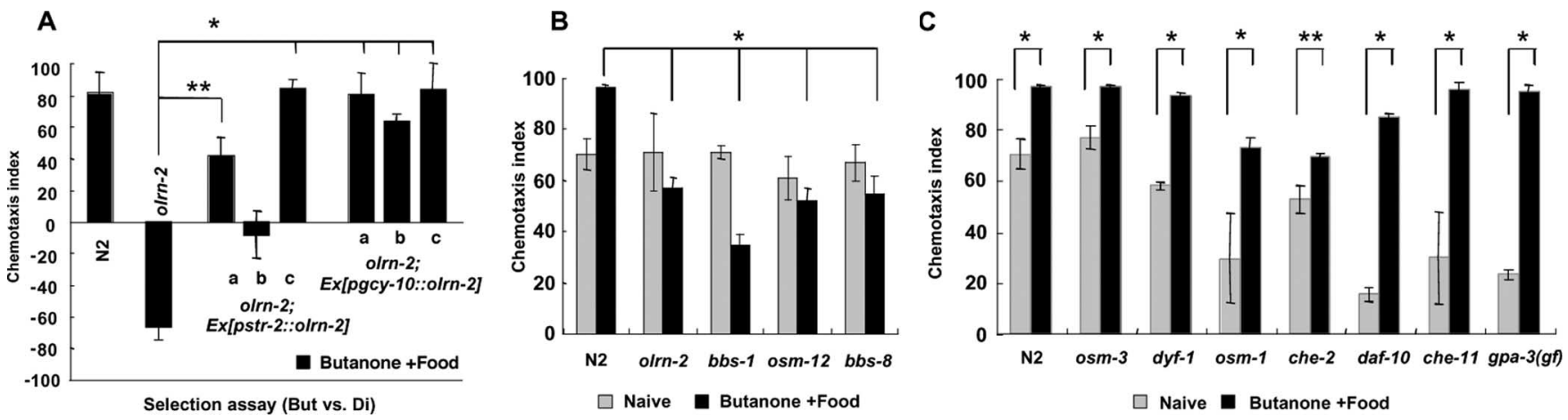

Figure 6. Bardet-Biedl syndrome genes are required for butanone enhancement in $A W C^{\circ \mathrm{N}}$ neurons, whereas other cilium structure genes are not required. $A$, Rescue of the olrn- 2 butanone enhancement phenotype with the wild-type olrn-2 CDNA driven by str-2 (AWC ${ }^{\mathrm{ON}}$ ) and $g c y-10$ (AWB and AWC) promoters. Results of three independent lines of animals carrying extrachromosomal array are shown for each promoter. The selection assay was used to detect the rescue sensitively. Four to six plates were used for all data. ${ }^{*} p<0.005$, ${ }^{* *} p<0.05$, comparing olrn-2 animals with each line of olrn-2 animals carrying transgenes for butanone enhancement. $\boldsymbol{B}$, Mutants in Bardet-Biedl syndrome genes exhibited defects in butanone enhancement. olrn-2(ut306) is allelic to bbs-8(nx77), and osm-12 gene encodes the C. elegans BBS-7. Four to 15 plates were used for all data. C, Mutants in other cilium structure genes did not exhibit defects in butanone enhancement. $g p a-3(g f)$ is a strain with a chromosomal insertion of the gain-of-function (Q205L) mutant gpa-3 transgenes. Four to 15 plates were used for all data. The error bars indicate SEM.

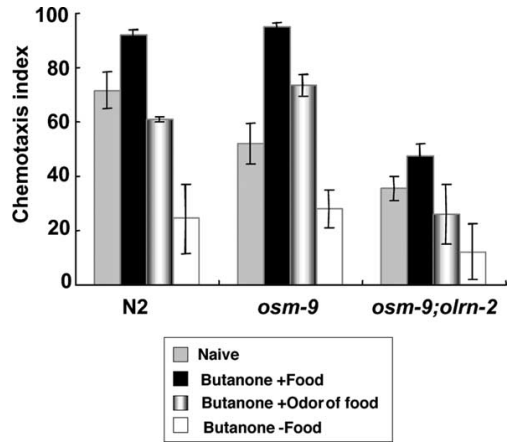

Figure 7. Butanone enhancement experiment with the odor of food instead of food. The chemotaxis indexes of wild-type (N2), osm-9, and osm-9;olrn-2 animals preexposed to butanone and the odor of food are shown, together with those of naive animals, animals preexposed to butanone and food, and animals exposed to butanone alone. The osm- 9 mutant was used to reduce the effect of butanone adaptation, which hindered the detection of chemotaxis enhancement by preexposure to butanone and the odor of food. The osm-9;olrn-2 double mutant was used as a negative control of the osm- 9 mutant. In all of these experiments, the amount of butanone and the time length for preexposure were exceptionally $0.24 \mu \mathrm{l}$ and 60 min to reduce the effect of butanone adaptation. Twelve plates were used for " $\mathrm{N} 2$, Butanone + Odor of food," 9 plates for "N2, Butanone - Food," 13 plates for "osm-9, Naive," and 15 plates for "osm-9, Butanone + Odor of food." Five to 15 plates were used for other data. ${ }^{*} p<0.005$, comparing wild-type animals preexposed to butanone and the odor of food with those preexposed to butanone alone. ${ }^{* *} p<0.05$, comparing osm- 9 animals preexposed to butanone and the odor of food with naive osm- 9 animals. The error bars indicate SEM.

Kimura, and I. Katsura, unpublished results). Even our failure to detect enhancement with some other odorants (benzaldehyde, diacetyl) might be attributable to technical reasons, for instance, attributable to premature enhancement of chemotaxis in naive animals by chemicals contained in the bacteria or the agar for worm cultures. The occurrence of this type of plasticity in multiple odorants is consistent with the idea that it is important in the behavior of C. elegans.

This type of plasticity may confer a selective advantage to $C$. elegans under natural conditions. Bacteria produce a variety of odorants, whose concentrations depend on the species of bacteria and environmental conditions (Sondergaard and Stahnke, 2002). This type of plasticity may enable C. elegans to migrate efficiently to those bacteria that produce the same odorants as it has met shortly before.

Butanone enhancement is similar to classical conditioning in a certain aspect: it integrates two sensory signals to change behav-
Table 1. Phenotypes of mutants in some genes controlling the $\mathrm{AWC}^{\mathrm{ON}} / \mathrm{AWC}^{\mathrm{OFF}}$ fate

\begin{tabular}{|c|c|c|c|c|c|}
\hline Phenotype & Wild-type & olrn-1 & daf-11 & nsy-1 & olrn- $2^{a}$ \\
\hline \multicolumn{6}{|l|}{ Enhancement } \\
\hline Butanone & Normal & Abnormal & Abnormal & Normal & Abnormal \\
\hline \multicolumn{6}{|l|}{ Adaptation } \\
\hline Butanone & Normal & Normal & Normal & Abnormal & Normal \\
\hline Benzaldehyde & Normal & Abnormal & Normal & Normal & Normal \\
\hline \multicolumn{6}{|l|}{ Chemotaxis } \\
\hline 1:10 butanone & Normal & Normal & Normal & Normal & Normal \\
\hline 1:1000 butanone & Normal & Abnormal & Abnormal & Normal & Normal \\
\hline \multicolumn{6}{|l|}{ Expression } \\
\hline str-2 expression & $10 \mathrm{~N} / 1 \mathrm{OFF}$ & $20 \mathrm{FF}$ & $20 \mathrm{FF}$ & $20 \mathrm{~N}$ & $10 \mathrm{~N} / 10 \mathrm{FF}$ \\
\hline
\end{tabular}

The results show the diversity of AWC neurons concerning the sensitivity and plasticity to various odorants.

${ }^{a}$ The olrn-2 gene does not control the AWC ${ }^{\mathrm{ON} / \mathrm{OFF}}$ fate but is added to this table for comparison.

ior in a direction that is beneficial to the animal's survival and proliferation. However, it also has properties different from those of classical conditioning. First, naive animals already have tendency to migrate to butanone, and preexposure to butanone and food only enhances this tendency. Second, the enhancement of chemotaxis occurs when animals are preexposed to butanone and food at the same time, and not first to butanone and then to food.

The regulatory pathway including NSY-1 and DAF-11 produces the diversity of AWC neurons concerning olfactory sensation and plasticity

The $\mathrm{AWC}^{\mathrm{ON}} / \mathrm{AWC}{ }^{\mathrm{OFF}}$ cell-fate determination is known to produce the diversity of AWC neurons concerning the sensation of dilute butanone and dilute 2,3-pentanedione as well as the expression of str-2 (Wes and Bargmann, 2001). This study revealed that the diversity is larger than the two fates, $\mathrm{AWC}^{\mathrm{ON}}$ and $\mathrm{AW}$ $\mathrm{C}^{\mathrm{OFF}}$, if we consider difference in plasticity (Table 1). The AW$\mathrm{C}^{\mathrm{OFF}}$ neuron of olrn-1 mutants is different from that of the daf11(m84) mutant in adaptation to benzaldehyde, whereas the $\mathrm{AWC}^{\mathrm{ON}}$ neuron of the nsy-1 (ky542) mutant is different from that of the wild-type animal in adaptation to butanone. Thus, butanone enhancement is one of the many odor-related functions controlled by NSY-1 and DAF-11. The abnormality of butanone enhancement in olrn-1 mutants is not caused by the reduced sensation of butanone, because other mutants that show lower chemotaxis indexes exhibit normal butanone enhancement (Fig. $6 B)$. How NSY-1 and DAF-11 control all of these functions is an 
intriguing issue for future studies. If they control each function separately, there must be an evolutionary reason why such relationships were made. In contrast, if they regulate these functions by controlling one or a few key molecules, the control mechanism must be closely related to the issue how the sensation and plasticity of different odorants are controlled in a different manner in AWC neurons, whereas all of the sensory signals are transduced by cGMP signaling. In any case, AWC diversity is required for maximum plasticity in the olfactory response.

It also remains to be studied whether experience or neuronal activity alters the properties of AWC neurons through a mechanism involving NSY-1 or DAF-11 and thereby changes behavior in wild-type animals. This hypothesis may be interesting, considering that CGMP transduces sensory signals in AWC neurons (Komatsu et al., 1999; L'Etoile and Bargmann, 2000) and that the expression of str-2 is affected by neuronal activity in other sensory neurons (Peckol et al., 2001).

\section{Functions of Bardet-Biedl syndrome genes, but not other cilium structure genes, are required for butanone enhancement}

The olrn-2/bbs-8(ut306) mutant showed abnormality in butanone enhancement, which was rescued by the expression of the wild-type olrn-2 gene in the AWC ${ }^{\mathrm{ON}}$ neuron. Mutants in other Bardet-Biedl syndrome genes also exhibited abnormality, but mutants in other classes of cilium structure genes did not. The latter genes include those producing components of intraflagellar transport (IFT) particles (IFT-A: DAF-10, CHE-11; IFT-B: OSM-1, CHE-2), an IFT motor kinesin (osm-3), and a protein for docking IFT particles with OSM-3 kinesin (DYF-1) (Rosenbaum and Witman, 2002; Ou et al., 2005). Thus, butanone enhancement seems to require a $\mathrm{BBS}$-specific function at the $\mathrm{AWC}^{\mathrm{ON}}$ cilium. It is known that IFT particles break down into two subcomplexes IFT-A and IFT-B in $b b s-7$ and $b b s-8$ mutants (Ou et al., 2005). Whether this abnormality is the cause of the defect in butanone enhancement remains to be studied. Because functional difference between BBS genes and other cilium structure genes has not been elucidated, the results of this study may give a hint to the mechanism of Bardet-Biedl syndrome.

Sensory cilia are structures that can change dynamically even in adult animals (Fujiwara et al., 1999). Many chemoreceptors, ion channels, and signal transduction components are localized at cilia, and their localization may be controlled by neuronal activity or the activity of signal transduction systems ( $\mathrm{Hu}$ et al., 2006). The relationship between butanone enhancement and these dynamic properties of sensory cilia remains to be studied.

\section{Roles of AWC neurons in butanone enhancement}

Butanone enhancement is considered to include butanone sensation, food sensation, integration of butanone and food signals, and formation of the memory, of which butanone sensation is known to occur in AWC neurons (Bargmann et al., 1993). Furthermore, the following arguments suggest that AWC neurons may also perform the other processes. (1) Whereas olrn-2 gene is considered by its phenotype to be involved in some of these processes, the expression of olrn-2 gene in the $\mathrm{AWC}^{\mathrm{ON}}$ neuron is sufficient for normal butanone enhancement. It remains to be studied whether olrn-2 gene acts cell autonomously, but cilium structure genes are likely to act cell autonomously, as shown for che-2 gene (Fujiwara et al., 1999). (2) As discussed above, chemotaxis enhancement by butanone and the odor of food, together with the phenotypes of osm-9 and lim-4 mutants, shows that AWC neurons are strong candidates of neurons that sense food in butanone enhancement. This may have connection with the finding that AWC neurons, together with ASK neurons, are required for the stimulation of egg laying by food (Sawin, 1996). (3) If food is sensed by AWC, it would be much easier to integrate the two signals within AWC neurons than to transmit them as separate signals in AWC to downstream neurons. (4) Specific enhancement of butanone chemotaxis suggests that it is AWC sensory neurons and not downstream interneurons that have the memory for changing the behavior.

Thus, AWC neurons (the AWC ${ }^{\mathrm{ON}}$ neuron) may perform all of the essential processes of butanone enhancement in which sensory cilia and $b b s$ genes may play an important role. Studies on butanone enhancement may clarify a new mechanism of sensory integration and offer an insight into the evolutionary origin and diversity of behavioral plasticity.

\section{References}

Alkema MJ, Hunter-Ensor M, Ringstad N, Horvitz HR (2005) Tyramine functions independently of octopamine in the Caenorhabditis elegans nervous system. Neuron 46:247-260.

Ansley SJ, Badano JL, Blacque OE, Hill J, Hoskins BE, Leitch CC, Kim JC, Ross AJ, Eichers ER, Teslovich TM, Mah AK, Johnsen RC, Cavender JC, Lewis RA, Leroux MR, Beales PL, Katsanis N (2003) Basal body dysfunction is a likely cause of pleiotropic Bardet-Biedl syndrome. Nature 425:628-633.

Bargmann C, Avery L (1995) Laser killing of cells in Caenorhabditis elegans. In: Methods in cell biology, Vol 48, Caenorhabditis elegans: modern biological analysis of an organism (Epstein HF, Shakes DC, eds), pp 225-250. San Diego: Academic.

Bargmann CI, Horvitz HR (1991) Chemosensory neurons with overlapping functions direct chemotaxis to multiple chemicals in C. elegans. Neuron 7:729-742.

Bargmann CI, Hartwieg E, Horvitz HR (1993) Odorant-selective genes and neurons mediate olfaction in C. elegans. Cell 74:515-527.

Battu G, Hoier EF, Hajnal A (2003) The C. elegans G-protein-coupled receptor SRA-13 inhibits RAS/MAPK signalling during olfaction and vulval development. Development 130:2567-2577.

Bettinger JC, McIntire SL (2004) State-dependency in C. elegans. Genes Brain Behav 3:266-272.

Blacque OE, Reardon MJ, Li C, McCarthy J, Mahjoub MR, Ansley SJ, Badano JL, Mah AK, Beales PL, Davidson WS, Johnsen RC, Audeh M, Plasterk RH, Baillie DL, Katsanis N, Quarmby LM, Wicks SR, Leroux MR (2004) Loss of C. elegans BBS-7 and BBS-8 protein function results in cilia defects and compromised intraflagellar transport. Genes Dev 18:1630-1642.

Brenner S (1974) The genetics of Caenorhabditis elegans. Genetics 77:71-94.

Byars CL, Bates KL, Letsou A (1999) The dorsal-open group gene raw is required for restricted DJNK signaling during closure. Development 126:4913-4923.

Chao MY, Komatsu H, Fukuto HS, Dionne HM, Hart AC (2004) Feeding status and serotonin rapidly and reversibly modulate a Caenorhabditis elegans chemosensory circuit. Proc Natl Acad Sci USA 101:15512-15517.

Colbert HA, Bargmann CI (1995) Odorant-specific adaptation pathways generate olfactory plasticity in C. elegans. Neuron 14:803-812.

Colbert HA, Bargmann CI (1997) Environmental signals modulate olfactory acuity, discrimination, and memory in Caenorhabditis elegans. Learn. Mem 4:179-191.

Colbert HA, Smith TL, Bargmann CI (1997) OSM-9, a novel protein with structural similarity to channels, is required for olfaction, mechanosensation, and olfactory adaptation in Caenorhabditis elegans. J Neurosci 17:8259-8269.

Davies AG, Pierce-Shimomura JT, Kim H, Van Hoven MK, Thiele TR, Bonci A, Bargmann CI, McIntire SL (2003) A central role of the BK potassium channel in behavioral responses to ethanol in C. elegans. Cell 115:655-666.

Duerr JS, Frisby DL, Gaskin J, Duke A, Asermely K, Huddleston D, Eiden LE, Rand JB (1999) The cat-1 gene of Caenorhabditis elegans encodes a vesicular monoamine transporter required for specific monoaminedependent behaviors. J Neurosci 19:72-84.

Fujiwara M, Ishihara T, Katsura I (1999) A novel WD40 protein, CHE-2, acts cell-autonomously in the formation of C. elegans sensory cilia. Development 126:4839-4848. 
Gomez M, De Castro E, Guarin E, Sasakura H, Kuhara A, Mori I, Bartfai T, Bargmann CI, Nef P (2001) $\mathrm{Ca}^{2+}$ signaling via the neuronal calcium sensor-1 regulates associative learning and memory in C. elegans. Neuron 30:241-248.

Hedgecock EM, Russell RL (1975) Normal and mutant thermotaxis in the nematode Caenorhabditis elegans. Proc Natl Acad Sci USA 72:4061-4065.

Horvitz HR, Chalfie M, Trent C, Sulston JE, Evans PD (1982) Serotonin and octopamine in the nematode C. elegans. Science 216:1012-1014.

Hu J, Bae YK, Knobel KM, Barr MM (2006) Casein kinase II and calcineurin modulate TRPP function and ciliary localization. Mol Biol Cell 17:2200-2211.

Ishihara T, Iino Y, Mohri M, Mori I, Gengyo-Ando K, Mitani S, Katsura I (2002) HEN-1, a novel secretory protein with an LDL receptor motif, regulates sensory integration and learning in C. elegans. Cell 109:639-649.

Jacob TC, Kaplan JM (2003) The EGL-21 carboxypeptidase E facilitates acetylcholine release at Caenorhabditis elegans neuromuscular junctions. J Neurosci 23:2122-2130.

Kass J, Jacob TC, Kim P, Kaplan JM (2001) The EGL-3 proprotein convertase regulates mechanosensory responses of Caenorhabditis elegans. J Neurosci 21:9265-9272.

Kodama E, Kuhara A, Mohri-Shiomi A, Kimura KD, Okumura M, Tomioka M, Iino I, Mori I (2006) Insulin-like signaling and the neural circuit for integrative behavior in C. elegans. Genes Dev 20:2955-2960.

Komatsu H, Jin YH, L'Etoile N, Mori I, Bargmann CI, Akaike N, Ohshima Y (1999) Functional reconstitution of a heteromeric cyclic nucleotidegated channel of Caenorhabditis elegans in cultured cells. Brain Res 821:160-168.

Kuhara A, Mori I (2006) Molecular physiology of the neural circuit for calcineurin-dependent associative learning in Caenorhabditis elegans. J Neurosci 26:9355-9364.

L'Etoile ND, Bargmann CI (2000) Olfaction and odor discrimination are mediated by the C. elegans guanylyl cyclase ODR-1. Neuron 25:575-586.

L'Etoile ND, Coburn CM, Eastham J, Kistler A, Gallegos G, Bargmann CI (2002) The cyclic GMP-dependent protein kinase EGL-4 regulates olfactory adaptation in C. elegans. Neuron 36:1079-1089.

Mello CC, Kramer JM, Stinchcomb D, Ambros V (1991) Efficient gene transfer in C. elegans: extrachromosomal maintenance and integration of transforming sequences. EMBO J 10:3959-3970.

Miyahara K, Suzuki N, Ishihara T, Tsuchiya E, Katsura I (2004) TBX2/TBX3 transcriptional factor homologue controls olfactory adaptation in Caenorhabditis elegans. J Neurobiol 58:392-402.

Mohri A, Kodama E, Kimura KD, Koike M, Mizuno T, Mori I (2005) Genetic control of temperature preference in the nematode Caenorhabditis elegans. Genetics 169:1437-1450.

Murakami H, Bessinger K, Hellmann J, Murakami S (2005) Agingdependent and -independent modulation of associative learning behavior by insulin/insulin-like growth factor-1 signal in Caenorhabditis elegans. J Neurosci 25:10894-10904.

Nagai T, Ibata K, Park ES, Kubota M, Mikoshiba K, Miyawaki A (2002) A variant of yellow fluorescent protein with fast and efficient maturation for cell-biological applications. Nat Biotechnol 20:87-90.

Nuttley WM, Atkinson-Leadbeater KP, van der Kooy D (2002) Serotonin mediates food-odor associative learning in the nematode Caenorhabditis elegans. Proc Natl Acad Sci USA 99:12449-12454.

Ou G, Blacque OE, Snow JJ, Leroux MR, Scholey JM (2005) Functional coordination of intraflagellar transport motors. Nature 436:583-587.

Peckol EL, Troemel ER, Bargmann CI (2001) Sensory experience and sensory activity regulate chemosensory receptor gene expression in Caenorhabditis elegans. Proc Natl Acad Sci USA 98:11032-11038.

Perkins LA, Hedgecock EM, Thomson JN, Culotti JG (1986) Mutant sensory cilia in the nematode Caenorhabditis elegans. Dev Biol 117:456-487.

Rankin CH, Wicks SR (2000) Mutations of the Caenorhabditis elegans brain-specific inorganic phosphate transporter eat-4 affect habituation of the tap-withdrawal response without affecting the response itself. J Neurosci 20:4337-4344.

Remy JJ, Hobert O (2005) An interneuronal chemoreceptor required for olfactory imprinting in C. elegans. Science 309:787-790.

Rose JK, Kaun KR, Chen SH, Rankin CH (2003) GLR-1, a non-NMDA glutamate receptor homolog, is critical for long-term memory in Caenorhabditis elegans. J Neurosci 23:9595-9599.

Rosenbaum JL, Witman GB (2002) Intraflagellar transport. Nat Rev Mol Cell Biol 3:813-825.

Saeki S, Yamamoto M, Iino Y (2001) Plasticity of chemotaxis revealed by paired presentation of a chemoattractant and starvation in the nematode Caenorhabditis elegans. J Exp Biol 204:1757-1764.

Sagasti A, Hobert O, Troemel ER, Ruvkun G, Bargmann CI (1999) Alternative olfactory neuron fates are specified by the LIM homeobox gene $\mathrm{lim}-4$. Genes Dev 13:1794-1806.

Sagasti A, Hisamoto N, Hyodo J, Tanaka-Hino M, Matsumoto K, Bargmann CI (2001) The CaMKII UNC-43 activates the MAPKKK NSY-1 to execute a lateral signaling decision required for asymmetric olfactory neuron fates. Cell 105:221-232.

Sawin ER (1996) Genetic and cellular analysis of modulated behaviors in Caenorhabditis elegans. $\mathrm{PhD}$ thesis, Massachusetts Institute of Technology.

Sawin ER, Ranganathan R, Horvitz HR (2000) C. elegans locomotory rate is modulated by the environment through a dopaminergic pathway and by experience through a serotonergic pathway. Neuron 26:619-631.

Sondergaard AK, Stahnke LH (2002) Growth and aroma production by Staphylococcus xylosus, S. carnosus and S. equorum-a comparative study in model systems. Int J Food Microbiol 75:99-109.

Starich TA, Herman RK, Kari CK, Yeh WH, Schackwitz WS, Schuyler MW, Collet J, Thomas JH, Riddle DL (1995) Mutations affecting the chemosensory neurons of Caenorhabditis elegans. Genetics 139:171-188.

Sulston J, Dew M, Brenner S (1975) Dopaminergic neurons in the nematode Caenorhabditis elegans. J Comp Neurol 163:215-226.

Sze JY, Victor M, Loer C, Shi Y, Ruvkun G (2000) Food and metabolic signalling defects in a Caenorhabditis elegans serotonin-synthesis mutant. Nature 403:560-564.

Tobin DM, Madsen DM, Kahn-Kirby A, Peckol EL, Moulder G, Barstead R, Maricq AV, Bargmann CI (2002) Combinatorial expression of TRPV channel proteins defines their sensory functions and subcellular localization in C. elegans neurons. Neuron 35:307-318.

Tomioka M, Adachi T, Suzuki H, Kunitomo H, Schafer WR, Iino Y (2006) The insulin/PI 3-kinase pathway regulates salt chemotaxis learning in Caenorhabditis elegans. Neuron 51:613-625.

Troemel ER, Sagasti A, Bargmann CI (1999) Lateral signaling mediated by axon contact and calcium entry regulates asymmetric odorant receptor expression in C. elegans. Cell 99:387-398.

Uchida O, Nakano H, Koga M, Ohshima Y (2003) The C. elegans che-1 gene encodes a zinc finger transcription factor required for specification of the ASE chemosensory neurons. Development 130:1215-1224.

Vellai T, McCulloch D, Gems D, Kovács AL (2006) Effects of sex and insulin/insulin-like growth factor-1 signaling on performance in an associative learning paradigm in Caenorhabditis elegans. Genetics 174:309-316

Wes PD, Bargmann CI (2001) C. elegans odour discrimination requires asymmetric diversity in olfactory neurons. Nature 410:698-701.

Wicks SR, Yeh RT, Gish WR, Waterston RH, Plasterk RH (2001) Rapid gene mapping in Caenorhabditis elegans using a high density polymorphism map. Nat Genet 28:160-164.

Zhang Y, Lu H, Bargmann CI (2005) Pathogenic bacteria induce aversive olfactory learning in Caenorhabditis elegans. Nature 438:179-184.

Zwaal RR, Mendel JE, Sternberg PW, Plasterk RHA (1997) Two neuronal G proteins are involved in chemosensation of the Caenorhabditis elegans dauer-inducing pheromone. Genetics 145:715-727. 